Vol 11, Special Issue 4, 2018

\title{
FORMULATION AND EVALUATION OF CHITOSAN NANOPARTICLES FOR IMPROVED EFFICACY OF ITRACONAZOLE ANTIFUNGAL DRUG
}

\author{
CHARANTEJA REDDY Y, JEGANATH S*, MUNI KUMAR U
}

Department of Pharmaceutics, School of Pharmaceutical Sciences, Vels Institute of Science, Technology and Advanced Studies, Pallavaram, Chennai, Tamil Nadu, India. Email: jeganaths@gmail.com

Received: 10 October 2018, Revised and Accepted: 11 December 2018

\section{ABSTRACT}

Objective: The main objective of the study was to formulate and evaluate the chitosan nanoparticles to improve the therapeutic efficacy of itraconazole by loading in nanoparticle drug delivery system. Designing the formulation of the drug itraconazole prolongs the therapeutic concentration of the drug in the blood and which will lower the frequency of dosing and also improves the efficacy of the drug.

Methods: Itraconazole nanoparticles are prepared by ionic gelation method; here, chitosan is used as polymer. The formulated nanoparticles are evaluated for external morphological studies by scanning electron microscope (SEM), drug content, in vitro drug release studies, as well as infrared (IR) spectral analysis.

Results: The Fourier transform IR spectra show that there was no interaction between drug and polymers; hence, they are compatible. Percentage entrapment efficiency, drug content, and percentage yield were higher for F3 formulation. The particle size analysis shows that every particle in the formulations gave the range of 148-227 nm, respectively; increasing in the particle size observed with varying concentration of polymer. SEM analysis of the nanoparticles shows that all the formulations were spherical and smooth with ideal surface morphology. As the concentration of polymer, the drug release decreased proportionally. The stability studies were carried out on the optimized formulation for 2 months at $30 \pm 2{ }^{\circ} \mathrm{C}$ and $60 \pm 5 \% \mathrm{RH}$ and $40 \pm 2^{\circ} \mathrm{C}$ and $75 \pm 5 \% \mathrm{RH}$; finally, it was observed that there was no change in drug content and in vitro drug release profile even after storage at $30 \pm 2^{\circ} \mathrm{C}$ and $60 \pm 5 \% \mathrm{RH}$ and $40 \pm 2{ }^{\circ} \mathrm{C}$ and $75 \pm 5 \% \mathrm{RH}$ for 2 months.

Conclusion: Itraconazole is one among the most widely used antifungal drugs. Designing the formulation of drug itraconazole prolongs therapeutic drug concentration in the blood and decreases dosage frequency and also enhances the efficacy of drug.

Keywords: Itraconazole, Nanoparticles, Ionic gelation method, Chitosan.

(C) 2018 The Authors. Published by Innovare Academic Sciences Pvt Ltd. This is an open access article under the CC BY license (http://creativecommons. org/licenses/by/4. 0/) DOI: http://dx.doi.org/10.22159/ajpcr.2018.v11s4.31723

\section{INTRODUCTION}

The current years have witnessed the extraordinary growth of research and application in the area of nanoscience. There is increased confidence that nanotechnology is applied to medicine. It will convey important advances in the diagnosis and treatment of various diseases [1].

\section{Nanotechnology carrier for targeted drug delivery systems}

The nano-based carrier molecules are more advantageous because it acted for both site specific and organ specific. Reaching the nano or micron range of particles makes them to be highly potential carriers in lots of biological molecules. The carrier's surface properties can be improved for targeted drug delivery [2].

Targeted nano-based drug carriers enhance half-life of the drug molecules, decrease drug toxicity, and provide effective drug distribution. Drug carriers guarantee to deliver drugs to many anatomic extremity of the body such as blood-brain barrier and tight epithelial junctions of the skin. Drug carriers effectively penetrate tumors due to their leaky constitution, containing pores which range from diameter 100 to $1000 \mathrm{~nm}$.

\section{Antifungal agents}

Antifungal agents are mainly defined as substance that kills or inhibits their growth or reproduction of fungi. An antifungal such as amphotericin B and ketoconazole, both effective against a broad spectrum of fungi, most probably these antifungals act by binding the sterols which are present in the fungal plasma membrane and alter its membrane permeability [3]. An invasive fungal infection is becoming an increased cause of human mortality and morbidity, particularly for immune compromised populations $[2,4]$. The fungal pathogens Cryptococcus neoformans, Candida albicans, and Aspergillus fumigatus collectively contribute to 1 million human deaths annually.

\section{EXPERIMENTAL METHODS}

\section{Materials}

Itraconazole was obtained from Sigma-Aldrich, Chennai, India. Chitosan was gotten from Sigma-Aldrich, Chennai, India. Every other chemical utilized was of the standard analytical review.

\section{Identification tests}

Solubility analysis

The spontaneous interaction of two or more substance to form a homogenous molecular dispersion is called as solubility [5]. $10 \mathrm{mg}$ of drug was dissolved in $10 \mathrm{ml}$ of different solvents at room temperature.

\section{Determination of melting point}

The melting points of drugs were determined by means of capillary technique. Observed value was compared with the reported standard value.

\section{Formulation of itraconazole nanoparticles}

Preparation of chitosan gel

Chitosan gel solution $(0.2 \% \mathrm{~W} / \mathrm{V})$ was prepared by dispersing $200 \mathrm{mg}$ of chitosan in $100 \mathrm{ml}$ of glacial acetic acid solution $(1 \% \mathrm{~V} / \mathrm{V})$ with continuous stirring of $2 \mathrm{~h}$. Further, the prepared solution was kept overnight for the formation of clear gel. 


\section{Ionic gelation method}

Itraconazole with constant concentration was added to different concentrations of the polymer prepared from the above chitosan gel to achieve 1:1, 1:2, 1:3, and 1:4 ratio. A different concentration $(0.1$ and $0.2 \% \mathrm{w} / \mathrm{v}$ ) of sodium tripolyphosphate solution was prepared and added dropwise to chitosan solution with continuous stirring for $1 \mathrm{~h}$ by sonication. The obtained suspension was centrifuged at 10,000 rpm for $10 \mathrm{~min}$. The pellets obtained were resuspended in deionized water by sonication, then centrifuged and dried at room temperature $[6,7]$. The different formulations of itraconazole nanoparticles are shown in Table 1.

\section{Characterization and evaluation of nanoparticles}

Production yield (\%)

The production yield of nanoparticles from different batches was calculated by the weight of dried final product with the drug and polymers initial total weight which is used for the preparation of nanoparticles [8].

$\% \mathrm{PY}=\mathrm{WO} / \mathrm{WT} \times 100$

Where, $\mathrm{PY}=$ Production yield; $\mathrm{WO}=$ Practical mass (nanoparticles); and $\mathrm{WT}=$ Theoretical mass (polymer + drug)

\section{Particle size analysis}

The particle sizes of nanoparticles, that are not visible in the optical microscope, were measured by scanning electron microscopy (SEM) using Malvern Particle Size Analyzer (Mastersizer 2000). Samples were prepared by dispersing the nanoparticles using required quantity of water to attain $5 \%$ obscuration. Particle size distribution data are used to determine the average particle size $[9,10]$

\section{Differential scanning calorimetry (DSC)}

DSC of itraconazole, chitosan, and nanoparticles of itraconazole chitosan was done using Shimadzu DSC-60 Calorimeter, Tokyo, Japan.

\section{Surface morphology}

Surface morphology and shape of nanoparticles are observed with the aid of SEM (JEOL-JSM-AS430, Japan). The prepared and dried nanoparticles mounted to a metal stub and were coated by conductive gold as sputter coater joined to the instrument $[11,12]$

\section{Drug entrapment and drug content}

Initially, the prepared nanoparticles were dissolved in distilled water and ultracentrifuged at 10,000 rpm for $30 \mathrm{~min}$ for determining encapsulation efficiency $[13,14]$. The liquid phases consist of free itraconazole that is measured by UV spectrophotometry at $269 \mathrm{~nm}$. The itraconazole entrapment efficacy is calculated by the below-mentioned formula.

Entrapment efficiency $(\%)=(\mathrm{Tp}-\mathrm{Tf}) 100 / \mathrm{Tp}$

Where, Tp is the total itraconazole used to prepare the nanoparticles and $\mathrm{Tf}$ is the free itraconazole in the supernatant.

Drug content was calculated as follows:

$\mathrm{DC}(\%)=\mathrm{A}-\mathrm{B} / \mathrm{C} \times 100$

Where, $\mathrm{DC}=$ Drug loading; $\mathrm{A}=$ Weight of drug loaded in nanoparticles; $\mathrm{C}=$ Total weight of nanoparticles; and B = Free Itraconazole.

\section{In vitro release studies}

Accurately weighed nanoparticle samples were added to a dialysis membrane and kept in the dissolution medium at $37 \pm 2^{\circ} \mathrm{C}$ with $50 \mathrm{rpm}$. $1 \mathrm{ml}$ of dissolution media was withdrawn every $1 \mathrm{~h}$ and supplanted by utilizing parallel amount of the liquid and keep up constant volume [15]. The withdrawn samples were analyzed at $269 \mathrm{~nm}$ using spectrophotometer.

\section{Stability studies}

Stability studies were employed as per the ICH guidelines at $30^{\circ} \mathrm{C} / 60 \%$ $\mathrm{RH}$ and $40^{\circ} \mathrm{C} / 75 \% \mathrm{RH}$ for the selected formulations for 60 days and evaluated for their drug content and in vitro dissolution profile $[16,17]$.

\section{RESULTS AND DISCUSSION}

\section{Solubility analysis}

Itraconazole showed good solubility in chloroform and DMSO; however, it displays insolubility in water. Solubility analysis is necessary because the drug must be dissolved in the solvents and the dissolution medium used.

\section{Melting point determination}

The melting point of the drug was observed at $166^{\circ} \mathrm{C}$. The obtained result consistent with the reported range $\left(164-168^{\circ} \mathrm{C}\right)$ and conforms to known standards, thereby shows purity of the drug used in the study.

\section{Compatibility studies}

IR study

FT-IR spectroscopy study was used to check the compatibility between the drug itraconazole and the polymer chitosan used for the preparation of itraconazole nanoparticles. The obtained IR spectrum of the pure itraconazole was compared with functional group frequencies of standard. The results proved that there were no significant interactions between the drug and chitosan. The results are shown in Figs. 1-3.

\section{DSC}

Thermal behavior of itraconazole in nanoparticles was studied using DSC to observe the effect of polymer on itraconazole. The results are shown in Figs. 4-6.

\section{Characterization and evaluation of nanoparticles}

Production yield (\%)

The percentage yields of nanoparticles were observed in the range of $89-95.12 \%$. It was found that production yield of nanoparticles prepared by 1:3 concentrations showed greater production yield than the other prepared concentrations. The results are shown in Table 2 .

\section{Entrapment efficiency and drug content}

The entrapment efficiency and drug content of different formulations are shown in Table 3. It was observed that the formulation F3 gave the highest entrapment efficiency and drug content.

\section{Particle size analysis and zeta potential}

Particle size and zeta potential of all the formulations are shown in Table 4. The particle size analysis was carried out using optical microscopy and zeta potential will be measured using Malvern instrument. It shows that all formulations provided particles in the range of 148-227 $\mathrm{nm}$, respectively. Increasing in the particle size observed with varying concentration of polymer in increasing order

Table 1: Formulation of itraconazole nanoparticles

\begin{tabular}{lllll}
\hline Formulations code & Concentration of drug $(\mathbf{m g})$ & Conc. of polymer $\mathbf{( m g )}$ & Drug-polymer ratio & Conc. of TPP (\%) \\
\hline ICNP-1 & 100 & 100 & $01: 01$ & 0.10 \\
ICNP-2 & 100 & 200 & $01: 02$ & 0.10 \\
ICNP-3 & 100 & 300 & $01: 03$ & 0.20 \\
ICNP-4 & 100 & $01: 04$ & 0.20 \\
\hline
\end{tabular}




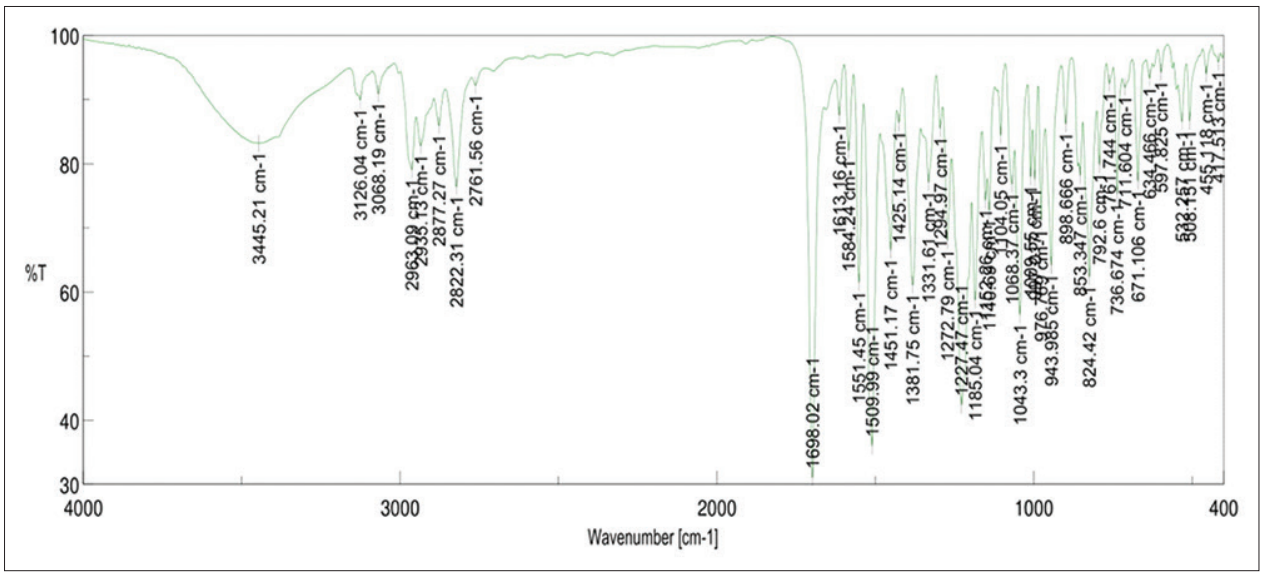

Fig. 1: Fourier transform infrared spectrum of pure itraconazole

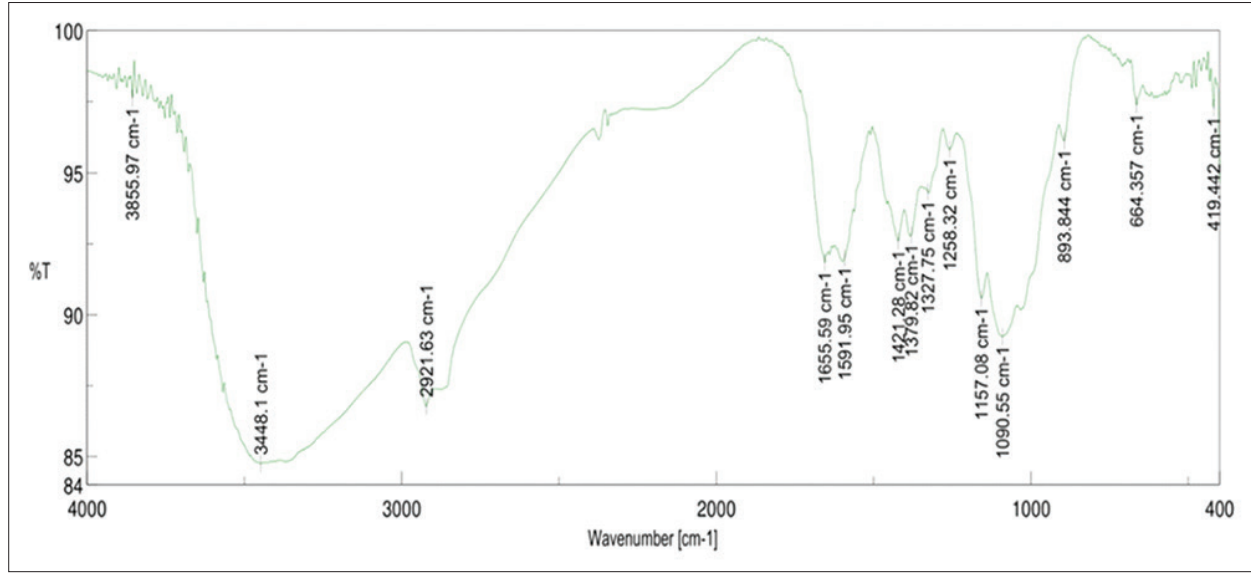

Fig. 2: Fourier transform infrared spectrum of chitosan

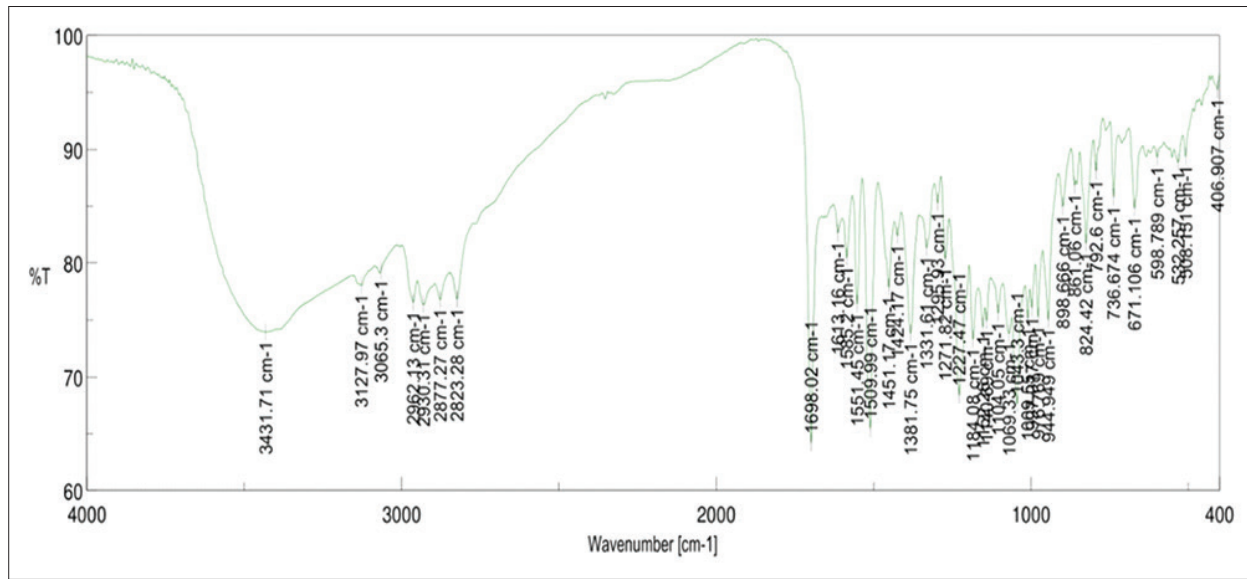

Fig. 3: Fourier transform infrared spectrum of itraconazole + chitosan

\section{Surface morphology}

SEM of the formulation F3 is shown in Fig. 7(a and b) which showed that the nanoparticles were discrete, spherical, and uniform with a smooth surface.

\section{In vitro release}

The in vitro release of itraconazole from prepared formulation of nanoparticles was studied using phosphate buffer at $\mathrm{pH} 7.4$ for $8 \mathrm{~h}$. The in vitro release data are shown in Table 5 , and the graphical representation is shown in Fig. 8.

\section{Stability studies}

Stability studies of the prepared itraconazole nanoparticles were carried out by storing the optimized formulation $\mathrm{F} 3$ at $30 \pm 2{ }^{\circ} \mathrm{C}$ and $60 \pm 5 \% \mathrm{RH}$ and $40 \pm 2{ }^{\circ} \mathrm{C}$ and $75 \pm 5 \% \mathrm{RH}$ for 60 days. Two parameters, namely in vitro release studies and percentage drug content, were carried out. The results are presented in Tables 6 and 7. It was observed that there was no change in drug content and in vitro drug release profile even after storage at $30 \pm 2{ }^{\circ} \mathrm{C}$ and $60 \pm 5 \% \mathrm{RH}$ and $40 \pm 2^{\circ} \mathrm{C}$ and $75 \pm 5 \%$ RH for 60 days. 


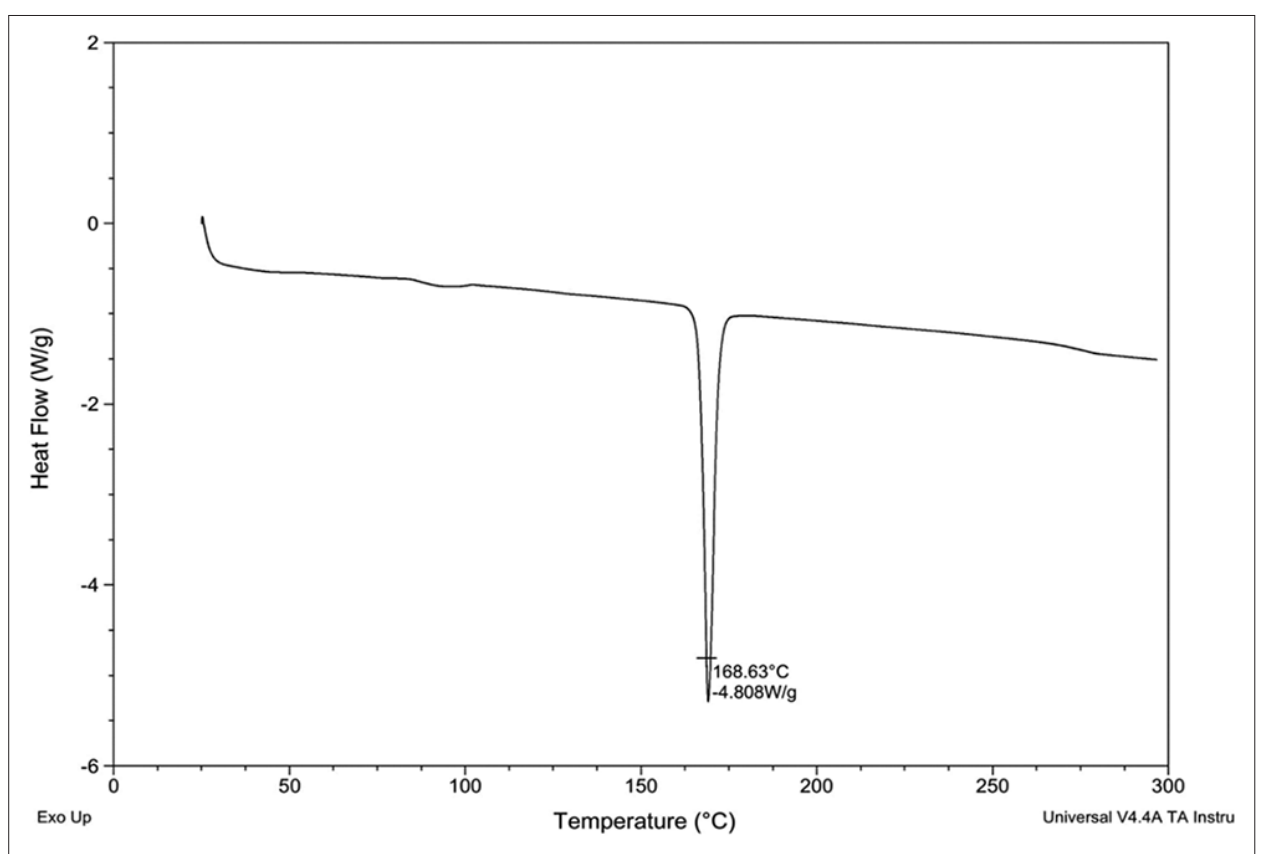

Fig. 4: Differential scanning calorimetry of itraconazole

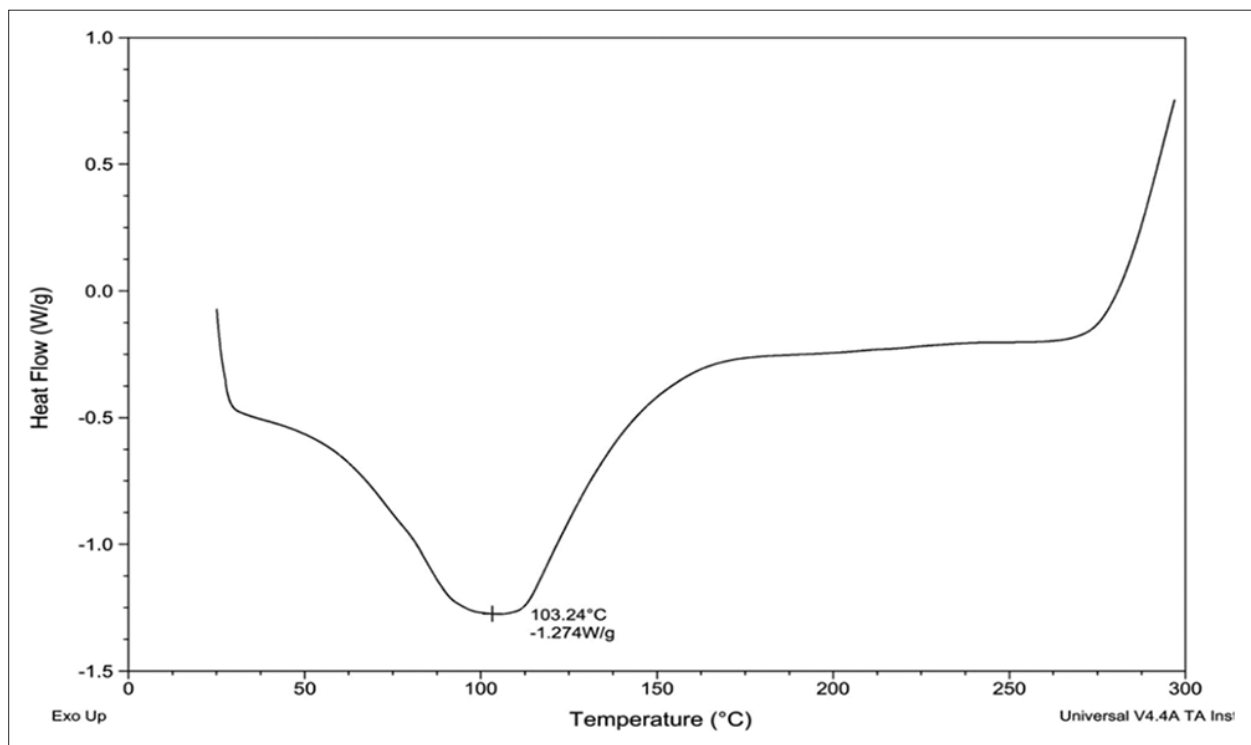

Fig. 5: Differential scanning calorimetry of chitosan

Table 2: Production yield of different formulations

\begin{tabular}{ll}
\hline Formulations & Percentage yield (\%) \\
\hline ICNP1 & 91.6 \\
ICNP2 & 89.02 \\
ICNP3 & 95.12 \\
ICNP4 & 93.74 \\
\hline
\end{tabular}

Table 3: Drug content and entrapment efficiency of different formulations

\begin{tabular}{lll}
\hline Formulations & Drug content & Entrapment efficiency (\%) \\
\hline ICNP1 & $76.25 \pm 0.3$ & $69.79 \pm 0.10$ \\
ICNP2 & $79.32 \pm 0.2$ & $75.33 \pm 0.30$ \\
ICNP3 & $81.12 \pm 0.3$ & $77.23 \pm 0.20$ \\
ICNP4 & $78.44 \pm 0.2$ & $74.12 \pm 0.10$ \\
\hline
\end{tabular}

Table 4: Particle size analysis of different formulations

\begin{tabular}{lll}
\hline Formulations & Particle size $(\mathbf{n m})$ & Zeta potential $(\mathbf{m V})$ \\
\hline ICNP1 & 148 & 10.6 \\
ICNP2 & 162 & 21.6 \\
ICNP3 & 188 & 32.1 \\
ICNP4 & 227 & 21.4 \\
\hline
\end{tabular}

\section{CONCLUSION}

Itraconazole is one of the most widely used antifungal drugs. Itraconazole nanoparticles are prepared by ionic gelation technique. Designing a sustained release formulation for the drug Itraconazole may prolong therapeutic concentration of drug in the blood and decrease frequency of dosing and also improve the therapeutic efficacy of drug. Hence, an attempt was made to formulate the nanoparticles antifungal drug. This study confirms that the ionic gelation technique is apt for 


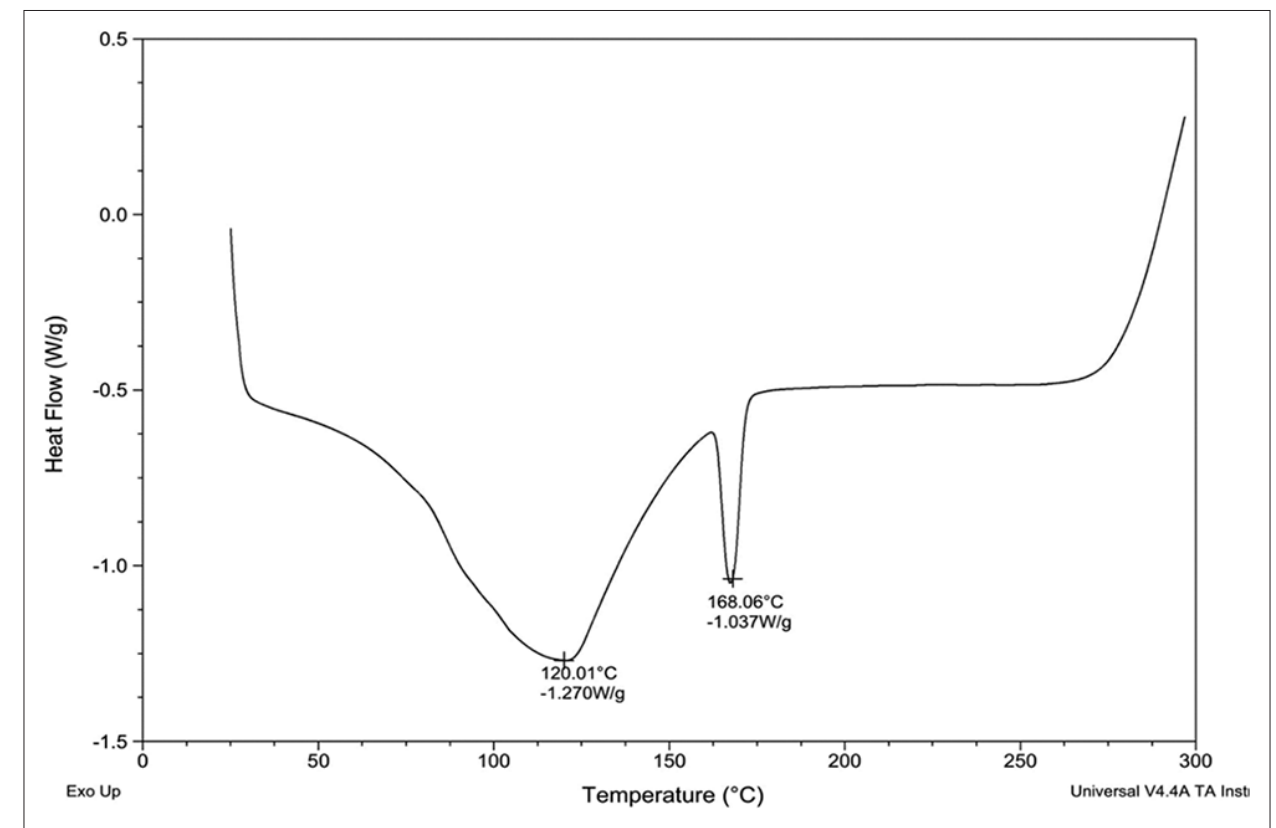

Fig. 6: Differential scanning calorimetry of a mixture of itraconazole and chitosan

Table 5: Comparative in vitro drug release of different formulations

\begin{tabular}{llllll}
\hline S. No & Time (h) & \multicolumn{2}{l}{ \% drug release } & & \\
\cline { 3 - 6 } & & ICNP1 & ICNP2 & ICNP3 & ICNP4 \\
\hline 1 & 0 & 0 & 0 & 0 & 0 \\
2 & 1 & 8.64 & 8.15 & 7.32 & 6.64 \\
3 & 2 & 17.25 & 15.38 & 16.38 & 14.32 \\
4 & 3 & 27.13 & 26.43 & 25.05 & 24.11 \\
5 & 4 & 39.06 & 38.06 & 37.62 & 34.84 \\
6 & 5 & 56.52 & 54.43 & 57.06 & 51.92 \\
7 & 6 & 67.25 & 64.79 & 63.96 & 65.29 \\
8 & 7 & 82.85 & 78.29 & 75.09 & 73.55 \\
9 & 8 & 91.03 & 89.51 & 85.92 & 83.21 \\
\hline
\end{tabular}

Table 6: In vitro drug release studies after storing at different temperatures (F3)

\begin{tabular}{|c|c|c|c|c|c|c|}
\hline \multirow[t]{2}{*}{ S. No } & \multirow[t]{2}{*}{ Time (h) } & \multicolumn{5}{|c|}{ Percentage $(\%)$ drug release } \\
\hline & & 0 day & 30 days & & 60 days & \\
\hline & & & $30^{\circ} \pm 2^{\circ} \mathrm{C}$ & $40^{\circ} \pm 2^{\circ} \mathrm{C}$ & $30^{\circ} \pm 2^{\circ} \mathrm{C}$ & $40^{\circ} \pm 2^{\circ} \mathrm{C}$ \\
\hline 1 & 0 & 0 & 0 & 0 & 0 & 0 \\
\hline 2 & 1 & 6.64 & 6.54 & 6.51 & 6.54 & 5.96 \\
\hline 3 & 2 & 14.32 & 14.2 & 14.15 & 13.8 & 13.7 \\
\hline 4 & 3 & 24.11 & 24.05 & 23.9 & 23.75 & 23.58 \\
\hline 5 & 4 & 34.84 & 34.73 & 34.65 & 34.22 & 33.8 \\
\hline 6 & 5 & 51.92 & 51.85 & 51.72 & 51.58 & 51.45 \\
\hline 7 & 6 & 65.29 & 65.21 & 65.05 & 64.96 & 64.8 \\
\hline 8 & 7 & 73.55 & 73.5 & 73.38 & 73.3 & 73.24 \\
\hline 9 & 8 & 83.21 & 83.15 & 83.08 & 82.95 & 82.9 \\
\hline
\end{tabular}

Table 7: Drug content after storing at different temperatures (F3)

\begin{tabular}{llllll}
\hline S. No & $\begin{array}{l}\text { Drug } \\
\text { content }\end{array}$ & \multicolumn{2}{l}{ Drug content } & \\
\cline { 3 - 5 } & & $\mathbf{3 0}^{\circ} \pm 2^{\circ} \mathbf{C}$ & & $\mathbf{4 0}^{\circ} \pm 2^{\circ} \mathbf{C}$ & \\
\hline \multirow{3}{*}{1} & 0 day & 30 days & 60 days & 30 days & 60 days \\
& $78.44 \pm 0.2$ & $78.38 \pm 0.12$ & $78.35 \pm 0.08$ & $78.26 \pm 0.01$ & $78.20 \pm 0.06$ \\
\hline
\end{tabular}

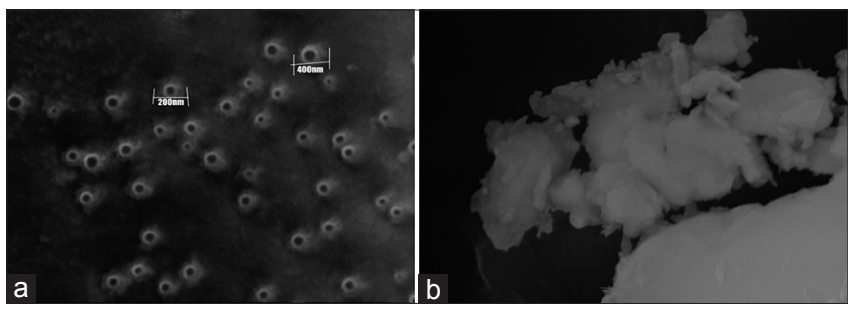

Fig. 7: (a) External morphological studies scanning electron microscope (SEM), (b) External Morphological Studies (SEM)

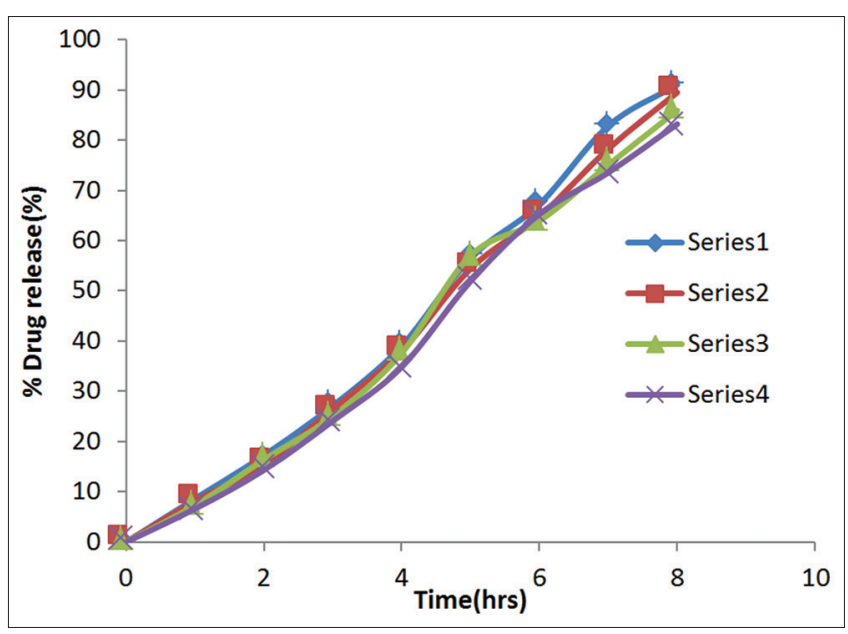

Fig. 8: Comparative in vitro drug release of different formulations

the preparation of itraconazole nanoparticles with more encapsulation efficacy. This formulation can be used to enhance the therapeutic efficiency of poorly water-soluble drugs. Thus, this study concluded that the itraconazole nanoparticles are suitable candidates that provide the best antifungal prolong action of the drug nanoparticles. 


\section{REFERENCES}

1. Jain NK. Controlled and Novel Drug Delivery. $1^{\text {st }}$ ed. New Delhi: CBS Publishers; 2005. p. 452.

2. Pappas PG, Kauffman CA, Andes D. Clinical practice guidelines for the management of candidiasis: Update by the infectious diseases society of America. Clin Infect Dis 2009;48:503-5.

3. Soppimath KS, Aminabhavi TM, Kulkarni AR, Rudzinski WE. Biodegradable polymeric nanoparticles as drug delivery devices. J Control Rel 2001;70:1-20.

4. Gevaria HB, Gami S, Patel N. Formulation and characterization of levofloxacin - Loaded biodegradable nanoparticles. Asain J Pharm 2011;1:114-9.

5. Yvette NK, Robert G, Eric A. Preparation and characterization of sterile and freeze-dried nanoparticles. Int J Pharm 2002;233:239-52.

6. Clisson ME, Pinto-Alphandary H, Ourevitch M, Andremont A, Couvreur P. Development of ciprofloxacin-loaded nanoparticles: A physicochemical study of the drug carrier. J Control Release 1998;56:23-32.

7. Abazinge M, Jackson T, Yang Q. Comparision of in vitro and in vivo release characteristics of sustained release of loxacin drug delivery. Drug Deliv 2000;7:77-81.

8. Benybaby N, Harsha NS, Jayaveera KN, Abraham A. Formulation and evaluation of levofloxacin nanoparticles by ionic gelation method. J Pharm Pharm Sci 2012;1:7-9.

9. Jeganath S, Senthilkumaran K. Development and evaluation of sustained release aceclofenac microspheres using chitosan polymers and techniques in management of rheumatoid arthritis. Int J Res Pharm
Nano Sci 2012;1:27-34.

10. Tamizhrasi1 S, Shukla A, Shivkumar T, Rathi V, Rathi JC. Formulation and evaluation of lamivudine loaded polymethacrylic acid nanoparticles. Int J Pharm Tech Res 2009;3:411-5.

11. Cetin M, Atila A, Kadioglu Y. Formulation and in vitro characterization of eudragit 1100 and eudragit L100-PLGA nanoparticles containing diclofenac sodium. Aaps Pharm Tech 2010;3:1250-6.

12. Zhang G, Niu A, Peng S, Jiang M, Fengtu Y, Li M, et al. Formation of novel polymeric nanoparticles. Accounts Chem Res 2001;34:249-56.

13. Leroux JC, Allémann E, De Jaeghere F, Doelker E, Gurny R. Biodegradable nanoparticles - from sustained release formulations to improved site specific drug delivery. J Control Release 1996;3:339-50.

14. Leroueil-Le Verger M, Fluckiger L, Kim YI, Hoffman M, Maincent P. Preparation and characterization of nanoparticles containing an antihypertensive agent. Eur J Pharm Biopharm 1998;46:137-43.

15. Song CX, Labhasetwar V, Murphy H, Qu X, Humphrey WR, Shebuski RJ, et al. Formulation and characterization of biodegradable nanoparticles for intravascular local drug delivery. J Control Release 1997;43:197-212.

16. Niwa T, Takeuchi H, Hino T, Kunou N, Kawashima Y. Preparations of biodegradable nanospheres of water-soluble and insoluble drugs with D, L-lactide/glycolide copolymer by a novel spontaneous emulsification solvent diffusion method, and the drug release behavior. J Control Release 1993;25:89-98

17. Ubrich N, Bouillot P, Pellerin C, Hoffman M, Maincent P. Preparation and characterization of propranolol hydrochloride nanoparticles: A comparative study. J Control Release 2004;2:291-300. 